\title{
Observation and Analysis of Characteristics of Wind and Air Temperature in Low Altitude Level in Panjin Wetland in Autumn and Winter
}

\author{
Yunhai Zhang ${ }^{1}$, Yangfeng Wang ${ }^{1}$, Hongbin Yang ${ }^{1}$, Jiwei $\mathrm{Xu}^{2}$ and Qiang Gong ${ }^{3}$ \\ ${ }^{1}$ Institute of Atmospheric Environment, CMA, Shenyang 110166, China \\ ${ }^{2}$ Dawa Meteorological Administration, Panjin 124200, China \\ ${ }^{3}$ Shenyang Regional Climate Center, Shenyang 110166, China
}

\begin{abstract}
Based on the low altitude observation data of Panjin wetland during the typical period from November 10 to 20,2015 , the characteristics of wind speed, wind direction and air temperature at low altitude, and the variation laws of altitude and stability of the atmospheric mixed layer were analyzed. By comparing the wind profile power exponent values using the observational data, the vertical variation laws of wind at low altitude were analyzed. Analysis results show that Panjin wetland and the surrounding areas have the same characteristics of wind and air temperature in low altitude level; with the increase in altitude in the wetland area, the wind speed increases gradually. There is an area with relatively stable wind speed at the altitude between 200 and $300 \mathrm{~m}$, where there is a wind shear. Under different stability conditions, the vertical wind speed profile is consistent with that in typical rural areas; the altitude of the mixed layer in the unstable level presents a distinct diurnal variation.
\end{abstract}

Keywords-panjin wetland; low altitude sounding; wind and air temperature characteristics; observation and analysis

\section{INTRODUCTION}

The diffusion and conveying of pollutants in the atmosphere depends mainly on the physical background of the atmosphere, and the structural characteristics of the atmospheric boundary layers. Owing to its special underlying surface types, wetland is a multi-functional ecosystem, and it is an important component part of a terrestrial ecosystem. Wetland interacts with the atmosphere through the continuous exchange of energies such as sensible heat, latent heat, and momentum, forming its unique climatic environment. Through the changes of vegetation, water and other underlying surfaces, wetland is involved in the atmospheric moisture, aerodynamic and other physical cycle processes, directly or indirectly affecting the air temperature and humidity changes, the vertical energy cycling and aerodynamic changes in the atmosphere of the entire region, and further influencing the regional atmosphere diffusion capacity and atmospheric environment ${ }^{[1-}$ 3]. Panjin wetland is located in the lower reaches of Liaohe River, and near the Bohai Sea; due to unique geographical characteristics, it not only has the unique characteristics of the boundary layers, but also has some impact on the weather and climate in central Liaoning Province. Therefore, it is of great significance to understand the characteristics of the wetland boundary layers in autumn and winter, and to carry out observation and analysis in autumn and winter according to the characteristics of wetland, so as to understand the regional weather characteristics and the influences on weather development. In this paper, the characteristics of wind and air temperature in low altitude stratification at typical observation stations in the wetland in autumn and winter were analyzed by using real-time observation data of Panjin wetland.

\section{OBSERVATION}

\section{A. Observation Instruments}

The wind field observation was conducted using the wind measurement method with small balloon of single theodolite, together with wind profile radar. A TK II sonde was used for air temperature field observation. The observation site was located at the weather station of Dawa County, which was located in the center of the wetland, with a flat terrain and good representation.

\section{B. Observation Methods}

The observation of low altitude wind and air temperature was carried out 7 times a day, starting from 5:00 am to 11:00 pm, the observation interval was 3 hours, and the observation lasted 10 minutes every time. The observation period was 10 days from November 10 to 20, 2015. The observation altitude included 13 layers, namely $10 \mathrm{~m}, 25 \mathrm{~m}, 50 \mathrm{~m}, 100 \mathrm{~m}, 150 \mathrm{~m}$, $200 \mathrm{~m}, 250 \mathrm{~m}, 300 \mathrm{~m}, 400 \mathrm{~m}, 500 \mathrm{~m}, 600 \mathrm{~m}, 700 \mathrm{~m}$, and $800 \mathrm{~m}$. The observation data from the wind profile radar were automatically collected at an interval of 5 minutes. The effective altitude of observation was $1500 \mathrm{~m}$. The data from the conventional ground weather stations were air temperature, humidity, pressure, wind and other meteorological data.

\section{Data}

Total 56 groups of valid sounding data were obtained. Wind profile data were obtained in the same period, and total 315 groups were valid. At automatic stations, the information was collected hourly everyday automatically, and total 240 groups were obtained. 


\section{ANALysis OF OBSERVATION DAta AND RESUlts}

\section{A. Ground Meteorological Characteristics}

During the observation period, the weather in the wetland area was mainly cloudy and occasionally sunny with weak cold air occurring; however, there was no severe weather process occurring, and the weather background was relatively stable. At the Dawa station, there was $0.1 \mathrm{~mm}$ of trace precipitation on November 19, and no precipitation occurred in other days. The wind speed mostly ranged from $1 \mathrm{~m} / \mathrm{s}$ to $3.5 \mathrm{~m} / \mathrm{s}$, with its maximum value of $7.4 \mathrm{~m} / \mathrm{s}$, during the observation period. The humidity fell in the range of $60 \%-95 \%$ mostly during the observation period. The relative humidity was over $80 \%$ on November 13 at 6:00 am, and over 90\% from November 13 at 8:00 pm to November 15 at 7:00 am. The air temperature fluctuated little.

\section{B. Vertical Distribution Characteristics of Low Altitude Wind Round Meteorological Characteristics}

Figure 1 shows the curve of wind speed versus altitude. As can be seen from the figure, the wind speed increasing with altitude is the main trend. At the altitude below $200 \mathrm{~m}$, the wind speed is steadily increasing. At the altitude between 200 and $300 \mathrm{~m}$, there is an area with relatively stable wind speed, while at the altitude above $300 \mathrm{~m}$, the wind speed shows a rapid increase trend.

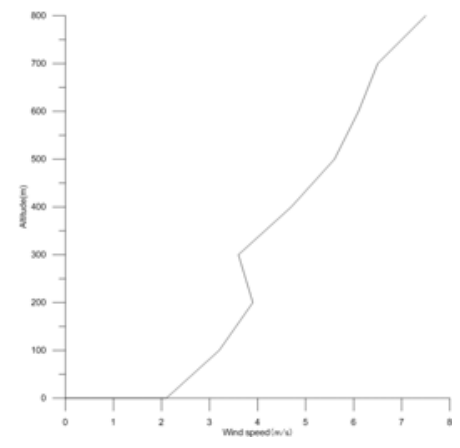

FIGURE I. CURVE OF WIND SPEED VERSUS HEIGHT

Table 1 shows the distribution of wind direction at different altitudes. At the altitude below $200 \mathrm{~m}, \mathrm{~N}, \mathrm{NNE}, \mathrm{NE}, \mathrm{ENE}$ and other northerly winds have larger wind frequency. Starting from the altitude of $200 \mathrm{~m}$, NNE is the dominant wind frequency; wind shear occurs at the altitude around $200 \mathrm{~m}$, and the wind frequency of S and SSW gradually increases above the altitude of $250 \mathrm{~m}$. At the altitude above $500 \mathrm{~m}$, the wind frequency in northerly direction is very small, and SSW and SW take up the dominant direction. The static wind frequency exists in each altitude layer, and it is the highest at the altitude of $10 \mathrm{~m}$ away from the ground. With the increase in altitude, the static wind frequency decreases rapidly above the altitude of $300 \mathrm{~m}$.

TABLE I. DISTRIBUTION OF WIND DIRECTION AT DIFFERENT ALTITUDES (\%)

\begin{tabular}{|c|c|c|c|c|c|c|c|c|c|c|c|c|c|c|c|c|c|}
\hline Altitude m & $\mathrm{N}$ & NNE & $\mathrm{NE}$ & ENE & E & ESE & $\mathrm{SE}$ & SSE & $S$ & SSW & SW & WSW & $\mathrm{W}$ & WNW & NW & NNW & $\mathrm{C}$ \\
\hline 10 & 9.68 & 11.16 & 12.99 & 10.24 & 9.7 & 2.7 & 1.46 & 6.31 & 4.33 & 2.36 & 3.32 & 1.97 & 5.47 & 1.68 & 2.99 & 2.66 & 10.98 \\
\hline 25 & 8.94 & 14.54 & 8.79 & 11.35 & 7 & 3.01 & 3.54 & 2.81 & 4.82 & 3.33 & 4.54 & 1.79 & 1.69 & 1.99 & 5.32 & 8.91 & 7.64 \\
\hline 50 & 5.98 & 15.01 & 4.9 & 14.16 & 11.12 & 4.18 & 3.41 & 3.92 & 4.32 & 5.22 & 3.77 & 3.35 & 2.27 & 1.13 & 2.8 & 7.6 & 6.86 \\
\hline 100 & 8 & 5.13 & 8.23 & 14.57 & 10.33 & 4.55 & 4.64 & 3.87 & 7.27 & 6.17 & 5.21 & 3.37 & 1.72 & 1.12 & 2.93 & 6.56 & 6.34 \\
\hline 150 & 7.64 & 6.73 & 9.43 & 10.86 & 7.55 & 3.44 & 3.43 & 4.33 & 9.89 & 6.26 & 5.36 & 3.12 & 1.44 & 6.46 & 2.54 & 6.33 & 5.18 \\
\hline 200 & 7.57 & 10.75 & 6.37 & 6.55 & 9.27 & 4.46 & 4.49 & 4.53 & 10.52 & 9.24 & 4.49 & 3.61 & 1.38 & 1.36 & 2.62 & 7.49 & 5.31 \\
\hline 250 & 10.5 & 9.33 & 6.4 & 7.42 & 6.59 & 4.53 & 5.33 & 5.23 & 12.31 & 8.72 & 5.34 & 3.64 & 1.76 & 1.02 & 1.57 & 3.64 & 6.68 \\
\hline 400 & 5.82 & 14.49 & 12.29 & 8.44 & 4.74 & 2.62 & 2.2 & 4.19 & 12.21 & 9.82 & 6.34 & 3.35 & 1.54 & 3.2 & 2.94 & 3.25 & 2.55 \\
\hline 500 & 9.45 & 9.81 & 13.21 & 11.59 & 2.5 & 1.29 & 3.12 & 3.12 & 6.2 & 10.21 & 12.7 & 5.98 & 1.68 & 2.1 & 2.51 & 2.13 & 2.39 \\
\hline 600 & 8.02 & 11.43 & 16.87 & 11.79 & 2.69 & 1.43 & 1.76 & 3.39 & 6.01 & 10.98 & 12.21 & 2.54 & 2.34 & 1.33 & 1.69 & 3.23 & 2.29 \\
\hline 700 & 11.93 & 4.98 & 5.12 & 5.76 & 3.98 & 1.42 & 1.64 & 1.91 & 5.46 & 17.86 & 14.25 & 10.54 & 3.36 & 2.55 & 3.66 & 3.31 & 2.27 \\
\hline 800 & 7.44 & 8.4 & 4.17 & 5.89 & 3.33 & 3.22 & 1.86 & 1.5 & 3.12 & 13.2 & 16.65 & 15.32 & 3.37 & 5.4 & 3.73 & 2.46 & 0.95 \\
\hline
\end{tabular}

The above analysis shows that the low altitudes of 200$300 \mathrm{~m}$ in the wetland are the main altitudes with variations of wind direction and wind speed, and the altitudes near the ground surface have relatively high occurrence probability of static wind and relatively small wind speed. The characteristics of low-altitude wind are basically consistent with those of lowaltitude wind in the surrounding areas of the wetland ${ }^{[4]}$.

\section{Using the Wind Profile Power Exponent to Simulate Wind Speed Variation with Altitude}

In general, the variation of wind with altitude in the nearground layer within an altitude of $10 \mathrm{~m}$ from the ground has a strong relationship with the underlying surface. The level state of the lower atmosphere is also an important factor determining the intensity of disturbance. The observation and analysis results show that the wind speed profiles are different due to the combined action of dynamic factors and thermal factors. When the atmosphere is stable, the wind speed increases with the altitude and it increases rapidly at the altitude of $150-250 \mathrm{~m}$, but the wind direction gradually turns westwards at the altitude of $500 \mathrm{~m}$ and above. The stable profile appears in the midnight to the next early morning. When the atmosphere is unstable, the wind speed profile becomes a relatively straight curve, and the unstable profile appears in the afternoon to the evening.

The wind speed at different altitudes can be calculated by using the near-ground wind speed profile exponent. The variation of the power exponent $\mathrm{m}$ also reflects the variation of atmospheric level ${ }^{[5-8]}$. The wind speed profile power exponent formula is as follows:

$$
U=U_{1} \times\left[\frac{Z}{Z_{1}}\right]^{m}
$$


where: $\mathrm{U}$ is the average wind speed calculated at the altitude of $\mathrm{Z}$, $\mathrm{U} 1$ is the average wind speed at the altitude of $\mathrm{Z} 1$ and $\mathrm{m}$ is the wind speed profile exponent.

When using conventional meteorological data, the atmospheric stability classes are based on the modified Pasquill stability classification method, and they include six classes, namely strongly unstable, unstable, weakly unstable, neutral, relatively stable, and stable, which are denoted as A, B, C, D, E, and $\mathrm{F}$, respectively. Table 2 shows the comparison between the measured values of wind speed profile exponent from fitting calculation and the national standard values (from rural areas). The calculated wind speed profile exponent values are basically consistent with the national standard values, but there is no measured value of class A.

TABLE II. WIND PROFILE EXPONENT VALUES AT DIFFERENT STABILITY CLASSES

\begin{tabular}{lcccccc}
\hline \multicolumn{1}{c}{ Stability } & A & B & C & D & E & F \\
\hline $\begin{array}{l}\text { Measured } \\
\text { value }\end{array}$ & & 0.08 & 0.12 & 0.17 & 0.26 & 0.29 \\
\hline $\begin{array}{l}\text { National } \\
\text { standard }\end{array}$ & 0.07 & 0.07 & 0.10 & 0.15 & 0.25 & 0.25 \\
\hline
\end{tabular}

\section{Analysis of Boundary Layer Air Temperature Profile}

The air temperature sounding data show that the diurnal variation law of boundary layer air temperature profile of the wetland is relatively remarkable. At the altitude of $300 \mathrm{~m}$ near the ground, the air temperature profile exhibits typical diurnal variation law owing to the influences of the underlying surface characteristics and the solar radiation. From 5:00 pm to 6:00 am of next day, the air temperature has an increase trend with height. From 5:00 am to 11:00 am, due to solar radiation, the ground temperature increases, and the temperature inversion at low altitude rises, and weakens gradually. From 11:00 am to 5:00 pm, the variations of low altitude level tend to be consistent. And at the altitude above $500 \mathrm{~m}$, the air temperature has a decrease trend with altitude.

According to the measured air temperature inversion, the altitude of the mixed layer under different stability conditions and at different times is calculated and obtained by using the dry adiabatic curve method (Table 3, Table 4).

TABLE III. VARIATION OF ALTITUDE OF MIXING LAYER (M) OVER TIME

\begin{tabular}{lcccccccc}
\hline $\begin{array}{c}\text { Time } \\
\text { (O'clock) }\end{array}$ & $\mathbf{5}$ & $\mathbf{8}$ & $\mathbf{1 1}$ & $\mathbf{1 4}$ & $\mathbf{1 7}$ & $\mathbf{2 0}$ & $\mathbf{2 3}$ & $\begin{array}{c}\text { Average } \\
\text { value }\end{array}$ \\
\hline $\begin{array}{l}\text { Altitude } \\
\text { of mixed } \\
\text { layer (m) }\end{array}$ & 119 & 142 & 184 & 772 & 565 & 342 & 242 & 338 \\
\hline
\end{tabular}

TABLE IV. ALTITUDE OF MIXED LAYER UNDER DIFFERENT STABILITY CONDITIONS (M)

\begin{tabular}{ccccc}
\hline Stability & A-B & C & D & E-F \\
\hline $\begin{array}{c}\text { Altitude of mixed } \\
\text { layer (m) }\end{array}$ & 745 & 371 & 212 & 115
\end{tabular}

It can be seen from the table that the altitude of the mixed layer is relatively low due to the occurrence of air temperature inversion in the near-ground layer and the stable level state of the near-ground layer in the morning. After the sunrise, the altitude of the mixed layer gradually rises with the uplift and disappearance of the air temperature inversion. At 2:00 pm, the average altitude of the mixed layer is $772 \mathrm{~m}$, it is the highest in a day, and then the altitude of the mixed layer decreases gradually. The altitude of the mixed layer shows significant diurnal variation, and the atmospheric conveying capacity in the vertical direction reaches its maximum in the afternoon. It can be seen from the altitude of the mixed layer under different stability conditions that when the atmosphere is in unstable level, the vertical conveying capacity is the strongest, and the average altitude of the mixed layer can reach $745 \mathrm{~m}$. The variation characteristics of the low altitude air temperature inversion and the altitude of mixed layer are also consistent with those in the surrounding areas of the wetland.

\section{CONCLUSIONS}

At the low altitude in the wetland area, the wind speed gradually increases with the increasing altitude, and the wind also changes from the northerly direction to the southerly direction. At the altitude below $200 \mathrm{~m}$, the wind speed steadily increases. The main wind direction is NNE and N. At the altitude between 200 and $300 \mathrm{~m}$, there is an area with relatively stable wind speed, and it is also the altitude at which the wind shear occurs. At the altitude above 500m, SSW and SW take up the dominant direction. Static wind frequency often occurs in the near-ground layer.

The wind speed profile exponent values calculated with the observation data are basically consistent with the national standard values, reflecting that the wind speed profile in the vertical direction is consistent with that in typical rural areas under different stability conditions.

The altitudes of the mixed layer under different stability conditions are different, and the maximum altitude of the unstable level is $745 \mathrm{~m}$. In the unstable level, the altitude of the mixed layer presents significant diurnal variation, the maximum altitude is at 2:00 $\mathrm{pm}$ in a day, averaged $772 \mathrm{~m}$, while the minimum altitude is at 5:00 am in a day, averaged $119 \mathrm{~m}$.

The characteristics of wind and air temperature in low altitude level in the wetland area are consistent with those in the surrounding areas.

\section{ACKNOWLEDGMENT}

The financial support of China National scientific research fund (41375146) and Scientific Research Special Fund for Public Service (GYHY201406031) are gratefully acknowledged.

\section{REFERENCES}

[1] Hu F., Hong Z. X., Chen J. Y. et al. Comprehensive Observation and Study on the Heterogeneous Atmospheric Boundary Layer in Baiyangdian Region: Introduction of Experiment and Analysis of Nearground Micrometeorological Characteristics [J] Chinese Journal of Atmospheric Sciences, 2006,30(5):883-893.

[2] Liu X. M., Hu F., Jiang J. H. et al. Energy Budget over the Water and Land Heterogeneous Surface in Baiyangdian Region. Chinese Journal of Atmospheric Sciences,2008, 32(6):1411-1418.

[3] Su C. X., Hu Y. Q. Cold Island Effect over Oasis and Lake [J]. Chinese Science Bulletin 1987, 10:756-758. 
[4] Zhang Y. H., Ma Y. J., Liu N. W., et al. Observations on Haze and Fog in Shenyang Area [J]. Ecology and Environment Sciences 2010, 19(11):2636-2641.

[5] Jiang W. M., Cao W. J., Jiang R. B. Air Pollution Meteorology Tutorial. Beijing: China Meteorological Press, 1993.

[6] Li Z. K., Pan Y. X., Sun R. Q. Principle and Application of Air Pollution Meteorology. Beijing: China Meteorological Press, 1985..

[7] HJT/2.2-93. Technical Guideline for Environmental Impact Assessment [S]. Beijing: China Environmental Science Press, 1994.

GB/T13201-91. Technical Methods for Making Local Emission Standards of Air Pollutants [S]. Beijing: Standards Press of China, 1991. 